\section{IMPACTOS AMBIENTAIS DO TURISMO ECOLÓGICO NO BRASIL ${ }^{1}$}

\section{Doris v. d. M. Ruschmann ${ }^{2}$}

RESUMO: A avaliação dos impactos ambientais do turismo ecológico apresenta-se como base para a determinação de medidas preventivas e corretivas, que visam conservar a atratividade e a originalidade das áreas com recursos naturais consideráveis. Neste estudo, avaliam-se os impactos da atividade no Brasil e sugere-se um planejamento intersetorial, que promova o desenvolvimento sustentável do turismo ecológico, baseado na determinação da capacidade de carga ("carrying capacity") dos recursos naturais. Esse planejamento visa a preservação dos ecossistemas, para o atendimento das expectativas dos novos segmentos do mercado turístico, que buscam turismo de aventura e o encontro com a natureza.

PALAVRAS-CHAVE: Turismo ecológico; Conservação ambiental; Impactos ambientais.

ABSTRACT: The evaluation of ecological tourism environmental impact seems as a base to determine preventive and corrective actions, which are taken to maintain the atractivity and the originality of areas with large natural resources. In this study the activity impacts are devaluated in Brazil and a intersectorial plan is suggested which can promote the continuos ecological tourism development, based on the natural resources carryng capacity. This the expectations of new segments of the touristical market which tend

1 Texto original, em alemão, publicado com o título "Uniweltbelastung durch oekotourismus in Brasilien", em PILLMANN, W. \& PREDL, S. (ed.). Strategies for reducing the environmental impact of tourism. Proceedings of ENVIROTOUR VIENNA. International Society for Enviromunental Protection, Viena, nov. 1992 p. 553-565.

2 Mestre em Ciências da Comunicação - Turismo. Professora do Curso de Turismo da Escola de Comunicaçōes e Artes da USP. Professora e Consultora de Pesquis e na Pós-Graduação do Curso Superior de Hotelaria do SENAC/CEATEL. End. para corresp.: Rua Água de Figueira, 52 - CEP 04923-000 - São Paulo SP - Brasil. Fax: (011) 514-6158.

\section{INTRODUÇÃO}

O Brasil destaca-se, mundialmente, pelas suas dimensões continentais $\left(8.511 .965 \mathrm{~km}^{2}\right)$ e por possuir as maiores áreas contínuas de florestas intocadas, nas quais vive o maior número de espécies de fauna e flora do planeta e, apesar dos graves casos de destruição das florestas, ainda é considerado o alicerce para o equilíbrio ecológico e climático da terra.

Atualmente, as dificuldades socioeconômicas conduzem o país à carência de recursos para os estudos da planificação ambiental, e à falta de físcalização e controle da desvatação das florestas. Geralmente, essa situação ocorre com objetivos econômicos, para o desenvolvimento das atividades ligadas à agricultura ou à pecuária.

Entretanto, pouca ou nenhuma atividade econômica apresenta condições intrísecas tão favoráveis, para a conciliação do desenvolvimento com o meio ambiente, quanto o turismo. E o turismo ecológico constitui o elo dessa tendência, que propicia a prática da educação ambiental e a volta harmônica ao convívio com a natureza, a qual o homem modemo tanto precisa (BODSTEIN, 1992).

Apesar de uma legislação atualizada, a implantação de equipamentos e de programas voltados para o turismo ecológico são desenvolvidos no Brasil sem o necessário controle e físcalização e, por isso, alguns deles causam uma série de impactos ao meio ambiente; comprometendo a sobrevivência dos ecossistemas e, conseqüentemente, a atratividade dos locais visitados.

Considerando como impacto ambiental todas as alterações que ocorrem nas propriedades físicas, químicas e biológicas do meio ambiente natural, causadas por qualquer forma de matéria ou energia resultante das atividades humanas, pretende-se, nesteestudo, ressaltar a importância dos impactos do turismo ecológico e propor algumas altemativas, que proporcionem um relacionamento equilibrado entre o turismo e os recursos naturais cenicamente favorecidos. 


\section{PATRIMÔNIO NATURAL E TURISMO ECOLÓGICO NO BRASIL}

As pressões mundiais, os preparativos e os resultados da realização da RIO-92 - Conferência das Nações Unidas sobre o Meio Ambiente e Desenvolvimento (United Nations Conference of Environment and Development - UNCED-92) fizeram com que se acentuassem, em nível nacional, os debates, estudos e propostas para 0 relacionamento harmonioso do turismo com o meio ambiente natural. Espera-se que os responsáveis pelo turismo, tanto do setor público como privado tenham assimilado os resultados dos debates e que as atividades e empreendimentos do turismo ecológico incorporem a conservação, a eficiência, a eqüidade no uso dos recursos naturais e o respeito às comunidades humanas tradicionais, aos objetivos dos programas e aos equipamentos que comercializam.

O crescente interesse em nível mundial pelos programas voltados para o turismo "de aventura" ou "verde", que proporcionam o contato direto do turista com a natureza, faz com que o Brasil se posicione como uma destinação ideal para este novo e promissor segmento do mercado turístico.

A EMBRATUR - Instituto Brasileiro de Turismo -, órgão oficial da atividade no país, elaborou uma legislação específica para o desenvolvimento do turismo ecológico e conceitua-o como sendo

as atividades desenvolvidas em localidades com potencial ecológico; de forma conservacionista, procuran ística com o meio ambiente, harmonizando as ações com a natureza e oferecendo aos turistas um contato intimo com os recursos naturais e culturais da regiäo, buscando a formaçāo de uma consciência ecológica nacional (EMBRATUR, 1991).

Esta mesma organização delimitou as áreas de interesse turístico do país, nas quais os programas e equipamentos ecológicos encontram uma variedade de ecossistemas que, pela sua beleza, conservação e exotismo, constituem um patrimônio único para a sua comercialização junto à demanda turística nacional e internacional. Estes recursos encontram-se espalhados em todo o território nacional e as áreas onde predominam são:

a) a floresta amazônica;

b) a mata atlântica; c) os $8.500 \mathrm{~km}$ de costa atlântica;

d) o cerrado;

c) o panlanal;

f) a caatinga;

g) os campos.

Os órgãos governamentais ligados ao meio ambiente demarcaram 34 parques nacionais, 23 reservas biológicas, 31 estações ecológicas, 6 reservas ecológicas que, em conjunto, correspondem a 16.915.640 ha - insuficientes, diante da extensão do país, para a conservação ambiental que se faz urgentemente necessária.

As regiōes da Amazônia e do Pantanal se destacam neste contexto pelo seu tamanho (ambas correspondem a quase $50 \%$ do território nacional), e nas quais o turismo ecológico é praticado mais intensamente (RUSCHMANN, 1992a).

Os alojamentos de selva (lodges) e os programas ecológicos oferecidos aos turistas proporcionam ex periências únicas e, certamente, inesquecíveis aos turistas. Os hotéis são rústicos, construídos com materiais da região, e sua arquitetura, integrada à natureza, associa a paisagem com os ecossistemas nos quais se localizam. Geralmente, situam-se em áreas de floresta densa, perto de rios e lagos e proporcionam maior ou menor conforto ao turista, conforme sua classificação.

Oacesso,

realiza-se por meio de barcos a motor, e a viagem pode durar de duas a quatro horas, de acordo com a distância do lodge do aeroporto mais próximo.

Os programas, com duração média de dois a quatro dias (há turistas que permanecem duas semanas), incluem uma série de atividades diurnas e noturnas, tais como safáris fotográficos, pescaria, banhos, passeios (de barco nos rios e de canoa nos igarapés) e apreciação de fauna e flora etc.

A intensidade da participação física dos turistas nas atividades é classificada de hard e soft, que também se aplica ao nível de interesse nos estudos do meio ambiente. Os turistas hard, geralmente são cientistas ou estudiosose, quandona floresta ou no pantanal, alojam-se de forma rudimentar, têm atividade física (caminhadas) intensa e pesquisam os pássaros, a flora, a composição dos solos, as comunidades indígenas etc. Os turistas soft são apreciadores casuais da natureza, 
e nas viagens ecológicas mesclam o interesse pela história natural com outras atividades recreativas. Preferem um nível de conforto mai sofisticado (luz elétrica e gelo para os seus drinques, providos por geradores movidos a óleo diesel), e as suas atividades físicas estão relacionadas com os passeios a pé, de canoa ou de barco a motor.

A intensidade dos impactos dessas atividades sobre os ecossistemas varia de acordo com a observação ou não dos limites da capacidade de carga (carrying capacity) de cada área, quando da construção dos lodges ou do número de pessoas que participam das atividades.

\section{IMPACTOS AMBIENTAIS DO TURISMO ECOLÓGICO}

No Brasil, os impactos ambientais do turismo ecológico não têm sido estudados de forma sistemática e as ocorrências, aqui citadas, são fruto de observações empíricas, relatórios de grupos de ambientalistas, de guias ecológicos e de empresários que organizam as viagens. Além disso, utilizam-se dados relativos aos estudos realizados em outros países da América Latina - Belize, Costa Rica, Equador, Mćxico e ilha Dominica (BOO, 1990), cujos produtos turísticos ecológicos apresentam semelhanças marcantes com os do Brasil, tanto na organização dos programas como nos impactos que provocam nos meios naturais e socioculturais.

Diante da impossibilidade de dissociar os impactos ambientais e suas conseqüências, sobre as comunidades humanas das localidades vizinhas, dos equipamentos de hospedagem citam-se, a seguir, tanto os impactos ambientais como os socioculturais do turismo ecológico.

\subsection{Impactos Positivos nos Ambientes Naturais e Socioculturais}

\section{Nos Ambientes Naturais}

Criação de áreas, programas e entidades (governamentais $e$ não-governamentais) de proteção da fauna e flora.

Ex.: Projeto TAMAR - Tartarugas Marinhas.
Nos Ambientes Socioculturais

a) Campanhas e programas de educação ambiental para crianças, adultos, turistas e moradores das localidades turísticas.

b) Desenvolvimento do "orgulho étnico". As comunidades receptoras passam a sentir orgulho da originalidade dos recursos naturais da sua localidade e das suas características culturais. Engajam-se nas campanhas preservacionistas, fiscalizam as ações destruidoras dos visitantes e atuam como guias dos passeios pelas matas.

c) Um estudo desenvolvido pela EMAMTUR - Empresa Amazonense de Turismo, junto às comunidades receptoras do turismo ecológico, demonstrou que estas se favorecem da atividade. Beneficiam-se, principalmente, no atendimento das suas necessidades básicas, utilizando os barcos que transportam os turistas para irem às cidades próximas em busca de alimentos, medicamentos e vestuário. Além de trabalharem nos equi pamentos e de fornecerem alimentos da região aos alojamentos ecológicos, tais como a farinha e frutas (EMAMTUR, 1992).

d) Ambientalistas se engajam nos programas de ecoturismo e atuam como guias e instrutores na orientação e educação ambiental das comunidades locais e dos turistas, e, muitas vezes, tornam-se proprietários e administradores dos seus próprios lodges.

\subsection{Impactos Negativos nos Ambientes Naturais e Socioculturais}

\section{Nos Ambientes Naturais}

a) Acúmulo de lixo nas margens dos caminhos e das trilhas, nas praias, montanhas, rios e lagos

b) Uso de sabonetes e de detergentes pelos turistas contaminam as águas dos rios e lagos, comprometendo sua pureza e a vida dos peixes e da vegetação aquática.

c) Contaminação das fontes e mananciais de água doce e do mar, perto dos alojamentos, provocada pelo lançamento de esgoto e lixo in natura nos rios e no oceano. 
d) Poluição sonora e ambiental provocadas pelos motores dos barcos e pelos geradores, que provêm energia elétrica para os lodges.

e) Coleta e quebra dos corais no mar e das estalactites e estagmites das grutas e cavernas para serem utilizados como souvenirs.

f) Alteração da temperatura das cavernas e grutas e o a parecimento de fungos nas rochas, causados pelos sistemas de iluminação.

g) Pintura e rasura nas rochas ao ar livre e dentro das cavernas e grutas, onde os turistas querem registrar a sua passagem.

h) Coleta e destruição da vegetação nas margens das trilhas e nos caminhos da floresta.

i) Erosão de encostas devido ao maltraçado e falta de drenagem das trilhas.

j) Alargamento e pisoteio da vegetação das trilhas e caminhos.

1) Ruídos que assustam e provocam a fuga dos animais dos seus ninhos e refúgios; por exemplo, palmas, tiros, assobios, música, apitos etc.

m) Os turistas alimentam os animais mais dóceis com produtos com conservantes que, constituindo uma dieta estranha à habitual, provocam doenças e até a sua morte.

n) O lixo eabandonode restos de comida ao ar livre, que atraem insetos e provocam mau cheiro.

o) Caça e pesca ilegais em locais e épocas proibidas.

p) Incêncio, nas áreas mais secas, provocados por fogueiras ou faíscas de isqueiros, fósforos ou cigarros.

q) Desmatamento para a construção dos lodges e de equipamentos de apoio.

r) Descaracterização da paisagem pela construção de equipamentos cuja arquitetura, material e estilo contrastam com o meio natural.

\section{Nos Ambientes Socioculturais}

a) Descaracterização das tradições e costumes das comunidades receptoras, cujos ritos e mitos muitas vezes são transformados em shows para os turistas;

62 b) Sentimentos de inveja e ressentimento frente aos hábitos e comportamentos diferentes dos turistas e à ostentação de tempo livre e dinheiro - muitas vezes escassos para os moradores das localidades (efeito demonstração).

c) Aumento dos preços das mercadorias e terrenos.

d) Migração de pessoaas originárias de regiões economicamente debilitadas para os novos pólos turísticos, em busca de empregos, provocando excedente na oferta de mão-de-obra e escassez de moradias.

Pelo exposto, percebe-se que os impactos negativos do turismo ecológico sobre o meio ambiente natural e sociocutural superam os positivos. Este fato não pode ser ignorado pelos órgãos governamentais e pelos empresários do setor, pois alguns danos são irreversíveis e comprometem a característica natural desses meios - motivo principal da vinda dos turistas, que buscam a experiência turística junto aos ambientes ecologicamente conservados. A título de sugestão, propõe-se algumasalternativas que poderão ser viabilizadas, a fim de proporcionar aos turistas a oportunidade de visitar os locais especialmente privilegiados pela natureza, sem comprometer a originalidade e a sobrevivência dos ecossistemas.

\section{ALTERNATIVAS PARA O RELACIONAMENTO HARMONIOSO DO TURISMO ECOLÓGICO COM O MEIO AMBIENTE NATURAL}

O exotismo e a diversidade dos recursos naturais do Brasil atraem uma demanda interna e externa significativa e estimulam a instalação de uma infra-estrutura hoteleira e de programas para o ecoturismo que, muitas vezes, comprometem, irremediavelmente, os recursos naturais que promoveram a sua criação.

A busca do equilíbrio necessário para o desenvolvimento da atıvidade que beneficie a conservação ambiental, as comunidades teceptoras e os turistas envolve, necessariamente, um planejamento multissetorial. Este planejamento deverá considerar que a conservafào dos recursos naturais de valor notável paisagístico deve atentar 
para o fato de que o meio ambiente é considerado patrimônio público e o aspecto da sua conservação ecológica deverá estar equilibrado com o uso comum pelo povo, possibilitando a todos os cidadãos o contato com a natureza. Entretanto, este direito não concede aos cidadãos comuns ou aos turistas (cidadãos em férias) a prerrogativa de agredir, devastar e destruir os locais que visitam, colocando em risco a beleza paisagística e os exemplares da fauna e flora.

Por isso, o equilibrio entre a natureza e o turismo, onde a primeira constitui a "matéria-prima" para o segundo, necessita ser regulado e disciplinado. Dentre as ações destinadas a promover um relacionamento harmonioso entre o turismo ecológico e a conservação ambiental, recomenda-se as descritas a seguir.

a) O desenvolvimento do turismo sustentável, definido por PEARCE \& TURNER (1990:24) como sendo

aquele que pretende maximizar e otimizar a distribuição dos benefícios do desenvolvimento econômico, baseado no estabelecimento e na consolidaçäo das condiçōes de segurança sob as quais se manterāo os serviços turisticos, a fim de que os recursos naturais sejam mantidos, restaurados e melhorados dentro de um futuro previsivel.

O turismo passa, atualmente, por um período caracterizado por uma nova sensibilidade, na qual se discute a necessidade do controle do turismo de massa e o desenvolvimento de outras formas, como o "altemativo", "brando" e "responsável". O turismo ecológico se insere nesse contexto e, seguindo a orientação dos demais, que apregoam a conservação da autenticidade dos meios naturais e das comunidades receptoras para as gerações futuras, encontra no desenvolvimento do turismo sustentável uma das alternativas para a conservação dos seus recursos naturais.

b) Determinação da capacidade de carga (carrying capacity) constitui a base para o planejamento do turismo nas áreas com recursos naturais de fragilidade e beleza consideráveis. LOZATO-GIO TART (1992:141) entende que a sua determinação é fundamental para o desenvolvimento de um turismo restritivo e capaz de "salvar" os recursos naturais ameaçados. Define-a como sendo "o número máximo de pessoas que um recurso turistico pode suportar, antes que ocorram impactos negativos no ambiente físico e social."
A fixação da capacidade de carga de determinando recurso natural depende dos seus aspectos físicos (clima, território, paisagem e recursos hídricos) e das características socioeconômicas, tanto dos turistas como das comunidades receptoras. No caso do turismo ecológico, a capacidade de carga deverá ser estabelecida dentro dos limites mais baixos possiveis, devido à alta fragilidade dos ecossistemas nos quais são implantadas as facilidades turísticas.

c) O zoneamento detalhado dos recursos naturais, identificando e classificando as diferentes áreas, de acordo com a fragilidade dos ecossistemas, permitirá o estabelecimento de critérios, que irão liberar ou proibir a sua utilização para o turismo ecológico. $\mathrm{Na}$ América Latina, utiliza-se o sistema de classificação de terras que divide as áreas naturais em sete zonas de manejo (ROA et al., 1986:191): intangivel, primitiva, de uso extensivo, de uso intensivo, histórico-cultural, de recuperação natural e de uso especial. Além disso, é preciso estudar e delimitar as áreas de acordo com suas caracteristicas específicas, tais como foram sugeridas pela SEMA - Secretaria do Meio Ambiente: áreas de ocorrência de fauna, de nidificação e pouso de aves de arribação, áreas de formações vegetais nativas associadas à fauna, áreas de ocorrência de mamíferos; e, de acordo com esses dados, determinar trilhas em mapas e marcos de orientação de campo nas áreas passíveis de receberem visitantes (SEMA, s.d.).

d) Educaşäo ambiental dos turistas e das comunidades receptoras apresenta-se como fundamental para a conservação ambiental das áreas onde ocorre o turismo ecológico. Apesar de renomados pesquisadores internacionais (KRIPPENDORF, 1977; WHELLER, 1992) se mostrarem céticos e não acreditarem que os turistas passem a sentir-se responsáveis pelos impactos que a sua presença (em massa) causa nos recursos naturais. É imprescindível que os turistas desenvolvam comportamentos sociais mais responsáveis e atitudes preservacionistas durante as suas viagens.

As comunidades receptoras deverão ser conscientizadas da importância da atividade em si e da conservação da autenticidade dos recursos naturais, pois deles depende o futuro turistico da localidade e, conseqüentemente, as suas oportunidades de emprego e de complementação do orçamento doméstico. 
e) Estudos de impacto ambiental (EIA) e seus respectivos relatórios (RIMAs) são instrumentos imprescindíveis para a conservação da autenticidade dos recursos naturais de interesse turístico. Estes estudos, realizados quando os equipamentos ainda estão na fase de projetos, são desenvolvidos por equipes interdisciplinares e determinam as diretrizes necessárias, de acordo com as peculiaridades dos projetos e das características ambientais da área onde pretendem ser instalados.

A legislação exige a elaboração de EIAs e RIMAs para marinas, loteamentos rurais e urbanos, estradas e também para os equipamentos de turismo e lazer. De acordo com o resultado dos estudos, os projetos poderão ser aprovados integralmente, sofrer algumas alterações ou então ter recusada a sua implantação, como ocorreu no caso da construção da Rodovia do Sol - uma estrada turística, que deveria ligar a região do planalto às praias do litoral norte do Estado de São Paulo.

f) Intensificação da fiscalização dos empreendimentos e programas voltados para o turismo ecológico. No Brasil, a responsabilidade oficial pela atividade corresponde à EMBRATUR - Instituto Brasileiro do Turismo - que atua em conjunto com o IBAMA Instituto Brasileiro do Meio Ambiente e dos Recursos Naturais Renováveis (EMBRATUR, 1991). A legislação brasileira do turismo prevê uma série de critérios e normas especificas para os equipamentos de hospedagem considerados ecológicos (lodges) que, apesar de bem elaborados, carecem da necessária fiscalização e controle, tanto quanto da implantação como na operação dos equipamentos.

g) Capacitação de recursos humıanos especialmente treinados para a operação de equipamentos e de programas ecológicos em muito contribuirá para a conservação dos recursos naturais utilizados para o turismo ecológico. Além do desenvolvimento de cursos de guias ecológicos, recomenda-se o treinamento das comunidades locais, cujos integrantes conhecem intensamente as áreas, e poderão participar dos programas como guias nas trilhas e caminhos da floresta, dar instruções sobre os perigos e as condições de sobrevivência na selva, através da utilizaçãode plantas e sementescomestíveis. Além disso, a floresta e os pantanais possuem encantos, magias e lendas que fascinam os turistas e ninguém melhor do que um nativo para contá-las, dando-lhes o tom, o suspense e o mistério característicos da selva.

\section{CONCLUSÃo}

O turismo ecológico, uma das formas do chamado turismo alternativo, opõe-se ao turismo de massa e caracteriza-se pela participação de um número reduzido de pessoas, e do conseqüente pequeno porte dos equipamentos, tanto os de hospedagem como os de transporte para os centros urbanos ou de locomoção dentro das áreas.

Por isso, tem sua viabilidade econômica questionada, uma vez que o turismo de massa, caracterizado pelo elevado número de visitantes e do gigantismo dos equipamentos receptivos, tem sido considerado a "tábua de salvação" para os países do Terceiro Mundo. O ingresso (em grande quantidade) das moedas fortes dos turistas estrangeiros tem sido apresentado como uma das formas para a solução dos graves problemas socioeconômicos, através da geração de empregos, entrada de divisas, do desenvolvimento regional, da distribuição de renda etc. (DRAGICEVIC, 1991:40).

Entretanto, esta linha de raciocínio é contestada por DIAZ (1992:232), que argumenta que, apesar de não serem quantitativamente significativos (e por definição não devem sê-lo), os empreendimentos de pequena escala (rurais, ecológicos) se apresentam como os mais viáveis para a maioria das regiões da América Latina. A grande distância dos mercados turísticos emissores internacionais e a queda do poder aquisitivo da demanda interna não viabilizam economicamente a construção de grandes complexos turísticos — tão em moda nos anos 70 e 80.

Diante disso, sugere-se a criação de "corredores turísticos", integrados por "células naturais", de pequena escala e alta qualidade arquitetônica e de serviços, com uma forte orientação mercadológica para os segmentos de hábitos, costumes e preferências similares, nas quais os aspectos visuais e ecológicos são altamente valorizados e protegidos (demanda turística qualitativa para atividades seletivas).

Trata-se de um novo direcionamento para a atividade turística que só terá êxito se os ambientalistas, os representantes de órgãos públicos do turismo, os empresários e a população das localidades 
determinarem juntos qual a evolução pretendida para a destinação, antes da tomada das decisões finais para a implantação dos equipamentos e atividades (RUSCHMANN, 1992b:47).

A criatividade, o espírito de inovação e de cooperação entre os pequenos e os médios empresários se apresentam, portanto, como as alternativas mais promissoras para o desenvolvimento do turismo ecológico, tornando-o economicamente viável, socialmente justo e ambientalmente sadio e sustentável.

\section{REFERÊNCIAS BIBLIOGRÁFICAS}

BODSTEIN, Luis Carlos de A. 1992. Conservação ambiental e desenvolvimento turístico no Brasil. Turismo em Análise, São Paulo, v. 3, n. 1, p. 99-112, maio.

BOO, Elizabeth. 1990. Ecoturismo. Potenciales y Escollos. Washington: WWF.

DIAZ, Edgar A. H. R. 1992. La planificación del sector turismo en Latinoamerica. Estudios y Perspectivas en Turismo, Buenos Aires, v. 1, n. 3, p. 226-33.

DRAGICEVIC, Miroslav. 1991. Towards sustainable tourism. In: CONGRÉS DE L'AIEST, 41. St. Gallen, Rapports, AIEST. v. 33.

EMAMTUR. Empresa Amazonense de Turismo. 1992. Impactos sociais dos alojamentos de selva nas comunidades da Amazônia. Manaus: EMAMTUR/FVA/EMBRATUR. (Relatório Preliminar).

EMBRATUR. Instituto Brasileiro de Turismo. 1991. Programa Ecoturismo. Brasilia: EMBRATUR (Versão Preliminar).

KRIPPENDORF, Jost. 1977. Les devorateurs de paysages. Lausanne: Heures.

LOZATO-GIOTART, J. P. 1992. Geographical rating in tourism development. Tourism Management, London, v. 13, n. 1, p. 141-44, march.

PEARCE, D. W. \& TURNER, R. R. 1990. Economics of natural resources and the environment. H. Hemptead (UK): Wheatsheaf.

ROA, Jesus G. et al. 1986. Recursos naturales y turismo. Mexico: Limusa.

RUSCHMANN, Doris v. d. M. 1992a. Ecological tourism in Brasil. Tourism Management, London, v. 13, n. 1, p. 125-28; march.

RUSCHMANN, Doris v. d. M. 1992b. Turismo sustentado para a preservação do patrimônio annbiental. Turismo em Análise, São Paulo, v. 13, n. 1, p. 42-5, maio.

SEMA. Secretaria do Meio Ambiente. s.d. Turismo em estaçōes ecológicas. Brasilia: SEMA.

WHELLER, B. 1992. Is progressive tourism appropriate? Tourism Management, London, v. 13, n. 1, p. 104-5, March. 